\title{
Findes der en dansk tradition for netbaseret undervisning?
}

\author{
Jorgen Bang \\ Lektor, mag.art. \\ Institut for Informations- og Medievidenskab \\ Aarhus Universitet \\ jbang@imv.au.dk
}

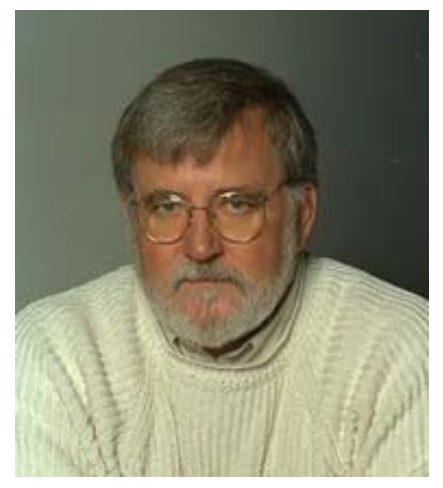

Jørgen Bang er lektor ved Institut for Informations- og Medievidenskab, Aarhus Universitet, og formand for universitetets udvalg for åben uddannelse. På internationalt plan har han deltaget $i$ adskillige EU-projekter, varet formand for nordisk forum for datastøttet loering (1991-95) og er siden januar 2002 prcesident for European Association for Distance Teaching Universities (EAD$T U)$. Har publiceret bøger og artikler inden for emnerne nordisk litteratur, fortcelleformer, mediereception, kommunikation i elektroniske netvark, laeringsteori og undervisningsteknologi.

\section{Netbaseret undervisning i historisk belysning}

Netbaseret undervisning er selvfølgelig undervisning via nettet - underforstået internettet. Logisk set har denne undervisningsform derfor ikke nogen historie som går længere tilbage ind til internettets etablering i 1960'ne - og i praksis ikke længere tilbage end til slutningen af 1980'ne, hvor undervisningsinstitutionerne fik e-mail- og internetadgang. Endvidere forudsætter netbaseret undervisning at der anvendes computere som kommunikationsredskab, og der skal vi frem til sidste halvdel af 1990'ne før almindelige husholdninger begynder at være koblet op til internettet. Når jeg alligevel vil gribe længere tilbage og begynde mit overblik med en redegørelse for fjernundervisningens udvikling, er det fordi denne tradition i høj grad sætter rammerne for den netbaserede undervisning.

\section{Fjernundervisning}

I mere end hundrede år har man forsøgt at udvikle en undervisningsform, der kunne tilgodese uddannelsesbehovet for voksne i beskæftigelse. Ved at anvende tidens kommunikationsteknologi har man løbende søgt at gøre udbuddet af undervisning uafhængigt af tid og sted. Frem til slutningen af 1960'ne var fjernundervisning identisk med brevskoler og korrespondancekurser, hvor al udveksling af materialer, opgaver og besvarelser foregik via post. I samme periode begyndte først radioen og siden tv at sende uddannelsesprogrammer målrettet direkte til skolebrug: skoleradio og -tv. 
I 1969 lancerede man i England et nyt universitetskoncept, "The Open University", baseret på fjernundervisning. Studiematerialerne blev udviklet med henblik på selvstudier og omfattede både særligt tilrettelagte tekster, læsevejledninger, øvelser (inkl. hjemmeeksperimenter), mm. og specielt producerede undervisningsprogrammer i radio og tv, som blev sendt af BBC. Samtidig blev der opbygget et net af studiecentre, hvor de studerende kan supplere deres selvstudier med seminarer og konsultationer - såkaldte "tutorials". Denne model har siden gået sin sejrsgang over det meste af verden og er fortsat det bedste bud på uddannelsesmæssig opgradering af store befolkningsgrupper uden mellem- og videregående uddannelse.

Parallelt med den industrialiserede uddannelsesmodel udvikledes i slutningen af 1980'ne et fjernundervisningskoncept, som udnyttede telekommunikationens nye muligheder. Audio- og videokonferencer anvendtes til overførsel af information og udveksling af synspunkter mellem studerende og lærere som var til stede samtidigt på adskilte lokaliteter - ofte i dertil indrettede studiecentre. Computerkonferencer via pc'er opkoblet i netværk tilbød en kommunikation der tillige var tidsuafhængig. Interaktionen mellem fjernstuderende var her det centrale. På grund af kommunikationsintensiteten er denne model særlig velegnet over for grupper af begrænset størrelse - op til 50-60 personer, mens den industrialiserede model tilbyder samme kursus til flere hundrede studerende på én gang.

Ud fra en pædagogisk synsvinkel er fjernundervisningens mest betydningsfulde bidrag til udviklingen skiftet i fokus fra "undervisning" som en lærercentreret aktivitet, til "læring" som en elev/studerendecentreret aktivitet. "The Open University" satte denne holdningsændring på spidsen, da det i 1969 som motto for dets aktivitet valgte: "not to teach, but to facilitate learning".

\section{Computer Supported Collaborative Learning}

En anden inspiration til netbaseret undervisning kommer fra udviklingen inden for området: Computer Supported Collaborative Learning - CSCL som er tæt forbundet med forskningsområdet: Computer Supported Cooperative Work - CSCW. Fokus for begge er udviklingen af ITløsninger til støtte for samarbejde om arbejdsopgaver herunder også systemer til arkivering, deling og distribution af viden.

Læringsmæssigt begyndte det i 1960'ne med udviklingen af computerbaserede læringsprogrammer under navne som "Computer Aided Instruction" (CAI), "Computer Supported Learning" (CSL) og "Computer Assisted Learning" (CAL). Pædagogisk set havde disse nærmest en behavioristisk forståelse af læreprocesser. Under indflydelse fra kognitivistiske og konstruktivistiske læringsteorier udvikledes i 70'ne og 80'ne mere intelligente og interaktive systemer - bl.a. Paperts “Logo-as-Latin. Først i 90'ne under indflydelse af teorier om situeret læring og social konstruktivisme udvikles CSCL som opskrift på samarbejde i on-line uddannelser (jf. L. Harasim 1988). Forskellige læringskoncepter understøttes af læringsplatforme til organisering af samarbejdet mellem de lærende indbydes og mellem lærende og vejledere.

Parallelt med den pædagogiske udvikling har den teknologiske udvikling flyttet fokus fra "standalone” og CD-ROM-baserede løsninger til netbaserede løsninger, hvor web-præsentation kan integreres med internet-diskussion. Inden for CSCL traditionen har man i mange uddannelsesmiljøer frigjort sig fra klasseværelset (øvelokalet, instruktionsrummet) og et lille "d" for "distributed" er på vej ind i forkortelsen: CSdCL - Computer Supported distributed Collaborative Learning (jf. A. Fjuk \& L. Dirckinck-Holmfeld 1997: 145-176). 


\section{E-læring}

Siden slutningen af 1990'ne har e-læring været det magiske ord for forsøg på at integrere koncepterne for IT-støttet fjernundervisning og CSCL. Samtidig har e-læring været ordet, der åbnede pengekasser for forsknings- og udviklingsprojekter. E-læring blev svaret på ikke bare uddannelsessektorens problemer, men også på læring i organisationer og på læring i et livslangt perspektiv.

En af grundene til e-læringsbegrebets succes hos politikerne var at det gav forhåbninger om at den rationaliseringsgevist, som IT havde muliggjort i store dele af produktions- og servicesektoren siden midten af 1980'ne, nu endelig kom til uddannelsessektoren. Disse forventninger diskuteres i en amerikansk bog fra år 2000 med den sigende titel: The "E" Is for Everything. ECommerce, E-Business, and E-Learning in Higher Education. (Richard N. Katz \& Diana G. Oblinger 2000). De dominerer også EU Kommissionens tankesæt i The eLearning Action Plan (2001):

E-learning is "the use of new multimedia technologies and the Internet to improve the quality of learning by facilitating access to resources and services as well as remote exchanges and collaboration. (...)

The first aim of the e-Learning initiative is to accelerate the deployment in the European Union of a high-quality infrastructure at a reasonable cost."

Synspunktet er, at når først e-læringsomgivelserne - netværket og adgangen til computere - er på plads løser resten af uddannelsessektorens problemer sig selv - ikke mindst de økonomiske.

At disse forventninger ikke er blevet indfriet endnu dokumenteres i en rapport fra samme år som OECD udarbejdede: E-Learning. The Partnership Challenge (2001):

"In spite of having spent US\$ 16 billion in 1999 in OECD countries on ICT, there is little evidence that ICT meets the original promise of better education for more people at less cost. As a result there are now concerns over the return investment.

(...) There is however no clear evidence that ICT investments made by the public sector have resulted in improved performance of teachers and/or learners, nor that it has improved the quality and access to educational resources on the scale predicted. Nonetheless, there is a general consensus that the ICT opportunity is still valid, and an acceptance as fact that ICT is part of daily life, forever changing the way people learn, work and play." (p. 24)

Rapporten udpeger det helt centrale dilemma, at der på den ene side ikke er de forventede besparelser i uddannelsessektoren ved at indføre IT, mens det på den anden side er oplagt at udnytte de nye muligheder for fleksibilitet og interaktivitet som IT-medier giver, i en uddannelsessammenhæng. Ikke mindst når befolkningen i stigende grad har adgang til computere og alligevel anvender dem til arbejde og underholdning.

Samtidig peger rapporten på at en del af problemet skyldes en overdreven teknologifiksering i implementeringen af mange IT-løsninger:

"Technology alone does not deliver educational success. It only becomes valuable in education if learners and teachers can do something useful with it. (...) 
It is a classic chicken and egg problem. The infrastructure, personal computer penetration and Internet connectivity must be in place for the software and applications to work. On the other hand just having the pipes in place with little or no educational software available generates disappointment and puts many teachers and learners off the online experiences altogether. (...)

Another aspect of the "global chicken and local egg" problem is that educational content does often not travel well across borders. What is appropriate and works in one culture does not necessarily translate to another. (...)

(...) educational content and e-learning services (...) need to be tailored to local needs and cultures." p. 24-25.

Hvor hele hardware-siden - computere, styresystem, netværksteknologi, mm. - produceres til et globalt marked, og hvor det samme gør sig gældende for en væsentligt del af softwareproduktionen f.eks. skriveprogrammer, regneark, databasesystemer, browsere og computerspil, dér skal uddannelsesprogrammer udvikles til et lokalt marked. Behov, normer og kulturelle værdier skal kunne bearbejdes i undervisningen med udgangspunkt i læringsmaterialerne, heriblandt også IT-baserede materialer. Samtidig er det vigtigt at læringsmaterialerne reflekterer den læringsforståelse som undervisningen er tilrettelagt ud fra.

Dette gælder også udviklingen af læringsplatforme. På markedet findes der mere end 200 kommercielle læringsplatforme der tilbyder et hav af forskellige funktionaliteter, hvoraf kun en begrænset mængde anvendes af den enkelte underviser og studerende (jf. Heilesen 2002: 79-86). Endvidere indeholder enhver læringsplatform et læringssyn - ofte uden at det er ekspliciteret. Når man anskaffer sig et e-læringssystem med en række ønskede funktionaliteter, køber man samtidig et pædagogisk koncept.

\section{Det danske koncept for netbaseret undervisning}

Ser man nærmere på situationen i Danmark i forhold til den skitserede generelle udvikling af netbaseret undervisning er der store lighedstræk, men også karakteristiske forskelle.

På grund af landets størrelse og andre geografiske forhold har vi aldrig udviklet en tradition for fjernundervisning på linje med vores skandinaviske naboer. I det 20. årh. har kun Hjemmeværnets uddannelse, militærets civiluddannelser og nogle få private organisationer tilbudt traditionel undervisning pr. korrespondance. Medvirkende til denne udvikling var også arven fra Grundtvig. Folkehøjskolens fokus på "det levende ord” har medført en skepsis over for undervisning som ikke udspringer at det aktive nærvær. Uddannelse er i Danmark en social aktivitet man er sammen om i klasseværelser! I praksis har der betydet at vi har opbygget en uddannelsesstruktur, hvor der sjældent er mere end 50 kilometer til nærmeste voksenuddannelsescenter.

Dedikerede fjernundervisningsinstitutioner der som Open University i England kunne opbygge en forskning inden for pædagogisk tilrettelæggelse af undervisningsmaterialer, formidling af viden og støtte til studerendes læreprocesser, har vi heller ikke etableret. Kun Danmarks Radio har udnyttet læringspotentialet i radio og tv - til skoleudsendelser og i enkelte forsøg med åbne universitetskurser, hvor der har været etableret et samarbejde med universiteterne. Det danske svar på voksnes behov for efter- og videreuddannelse med eksamen og tilrettelagt som deltidsstudier var at give universiteterne og andre videregående uddannelsesinstitutioner ret til at udbyde deltidsstudier inden for områder, hvor de også udbød fuldtidsstudier. Det skete i 1990 efter at universiteterne siden begyndelsen af 1980'ne på dispensation havde eksperimenteret med forskellige 
former for åben uddannelse - fjernundervisning, weekend undervisning, aftenundervisning. Karakteristisk for "Lov om åben uddannelse" er at det er en lov som regulerer adgangen til uddannelserne og finansiering af dem med taksametertilskud, men ikke berører undervisningsformerne. Der er således ingen forskel på støtten til kurser tilrettelagt fleksibelt som fjernundervisning og kurser, der afvikles som aftenundervisning med krav om tilstedeværelse.

Når jeg trækker finansieringsformen frem er det fordi den er med til sætte rammerne for udviklingen af undervisningsformerne i dansk fjernundervisning i første omgang, men siden hen også i dansk netbaseret undervisning. Der er intet incitament i finansieringsformen til at udbyde teknologistøttet uddannelse som kræver en initial investering i udviklingsomkostninger. Den bedste forretning gøres ved at udbyde samme undervisning som er leveret til fuldtidsstuderende i dagtimerne, som åben uddannelse til deltidsstuderende om aftenen mellem kl 17 og 21.

Når det alligevel er lykkedes at udvikle teknologistøttet fjernundervisning og netbaserede undervisningsformer i Danmark skyldes det forskellige udviklingsprojekter - danske, nordiske og europæiske (EU). I slutningen af 80'ne støttede undervisningsministeriet sammen med IBM Danmark et tidligt forsøg ved Jysk Åbent Universitet med brug af computer-konferencer i fjernundervisning. Det blev afgørende for den senere udvikling at netbaserede fjernundervisningsformer. Nationalt set skete det store spring fremad i midten af halvfemserne med etablering af Center for Teknologistøttet Uddannelse (CTU) hvor der blev skabt mulighed for at integrere IT i uddannelser på mange niveauer. Medvirkende til CTU's succes var sammenfaldet med udviklingen af www - der viste sig at være et fremragende undervisningsredskab - samt danskernes voksende tilkobling til internettet.

Projektmidler er gode til at udvikle og afprøve nye undervisningsformer, men de sikrer ikke en løbende drift af de gode løsninger. Når projektmidlerne er brugt fortsætter initiativerne kun hvis de udviklede undervisningsformer er udgiftsneutrale - eller bedre selvfølgelig: besparende - i forhold til de tidligere former. Danske uddannelsesinstitutioner er ikke i en situation hvor de kan investere i IT-støtte til undervisningen alene for at forbedre kvaliteten.

Mange havde håbet på at CTU var blevet videreført med en ny bevilling eller at der var blevet etableret en udviklingspulje til udvikling af e-læring eller andre former for virtuelle læringsmiljøer. "Det Virtuelle Universitet" (DVUNI) var et spædt forsøg i den retning, men blev standset midtvejs og var med sine 40 mill. kr. stærkt underfinansieret. Til sammenligning har man i Sverige afsat 500 mill. svenske kroner til udviklingen af "Netuniversitetet" og i Finland er et lignende beløb bevilliget til etableringen af det finske virtuelle universitet som et samarbejde mellem eksisterende institutioner. På grund af manglende ressourcer foregår der i dag kun få forsøg med at udvikle et dansk koncept for netbaseret undervisning. Et af dem er det it-vest-finansierede FLEXNET projekt.

Det største forhindring for udviklingen af netbaseret undervisning i Danmark er fraværet af en fælles læringsplatform der kunne understøtte udviklingen af undervisningsmaterialer og læringsaktiviteter tilrettelagt i forhold til dansk kultur og dansk pædagogisk tradition. I øjeblikket har stort set hver dansk uddannelsesinstitution eller amtslige og kommunale grupper af institutioner valgt deres eget kommercielle læringssystem. Det binder de studerende til institutionen fordi det er besværligt af skifte til et andet system, men det blokerer også for samarbejde mellem institutionerne. Det sidste er katastrofalt i et land på Danmarks størrelse! Samtidig bliver problemet ikke mindre af at de anvendte kommercielle systemer ikke understøtter samme pædagogiske læringskoncept og ikke er udviklet til at den danske tradition for læring. 


\section{Den konstruktive dialog}

Indirekte har jeg allerede svaret bekræftende på det indledende spørgsmål om der findes en dansk tradition for netbaseret undervisning, så lad mig prøve at identificere særpræget og forsøge at forklare dets opståen.

Som allerede nævnt har der ikke været basis for i Danmark at oprette institutioner som alene fokuserede på fjernundervisning og/eller netbaseret undervisning. Vores erhvervsvirksomheder er heller ikke så store at de har kunnet udvikle egne uddannelsesinstitutioner på linje med de "corporate universities" som kendes fra USA og England. Og danske forlag har kun i begrænset omfang satset på at udvikle IT-baserede undervisningsmaterialer til brug uden for skolesystemet. Alt $\mathrm{i}$ alt betyder dette at der ikke findes et dansk koncept for e-læring baseret på traditionelle forestillinger om vidensoverførsel som man bl.a. møder i koncepterne for "just-in-time learning", "justin-place learning" og "resource-based learning".

Dansk netbaseret undervisning eller e-læring er udviklet af undervisningsinstitutioner og har overordnet pædagogiske forståelse af læreprocesser fælles med det øvrige danske uddannelsessystem. Grundlæggende ses undervisning og læring i et konstruktivistisk perspektiv, hvor den aktive deltagelse af elever og studerende er helt central. Traditionel forståelse af læring som vidensoverførsel fra lærer til elev/studerende tages der afstand fra med betegnelsen "tankpasserpædagogik", selvom denne undervisningsform i praksis er på vej til at få en renæssance med det fornyede fokus på "klare mål" for de enkelte fag i bl.a. folkeskolen. I praksis kommer den konstruktivistiske grundholdning frem i den løbende konstruktive dialog om undervisningens faglige emne som udfolder sig på stort set alle niveauer i det danske uddannelsessystem, mellem lærer og elev/studerende og mellem elever/studerende indbyrdes. Det er i dialogen at den lærendes refleksion over nye informationer initieres og dermed bearbejdes i forhold til allerede eksisterende viden. Ofte anvendes projektarbejde i grupper som katalysator til at sætte dialogen i gang.

$\mathrm{Nu}$ fremhæver jeg denne dialogiske forståelse af læreprocesser som specifik dansk - og det er nok her den er trængt mest igennem - men den findes også i de andre Nordiske lande. Interessant er det imidlertid at det grundlæggende konstruktivistiske syn på læring på ingen måde er specielt dansk eller nordisk. De fremtrædende teoretikere inden for konstruktivismen kommer fra de store sprogområder: Dewey, Vygotsky, Engeström, Piaget, Glaserfeld, Luhmann m.fl. Den specifikt danske - og måske nordiske - dialogiske forståelse af læreprocessen synes af opstå i 1960'ne i brydningen mellem kulturradikal børneopdragelse og Piagets udviklingspsykologi i samspil med hans kognitionspsykologiske begreber om assimilering og akkomodation. Denne cocktail fænger og udvikler sig til den danske pædagogiske tradition, som den nuværende borgerlige regering nu forsøger at gøre op med i den såkaldte værdidebat.

Også inden for fjernundervisning slår den dialogiske tradition igennem da universiteterne i begyndelsen af 80 'ne begynder at eksperimentere med eksamensbaseret deltidsundervisning for voksne. De manglende udviklingsressourcer i samspil med den danske tradition for læring som en social aktivitet i dialog med lærer og medstuderende gør at man udvikler et koncept med "face-to-face" seminarer i kombination med selvstudieperioder. Ingen andre lande har tilrettelagt fjernstudier med så mange "obligatoriske" face-to-face seminarer som Danmark. I den netbaserede undervisning fastholdes det dialogiske element også - ja, man kan sige at nettet anvendes til at fastholde dialogen i selvstudieperioden. Antallet af face-to-face seminarerne er kun beskåret ganske lidt i forbindelse med at undervisningsforløbene understøttes af video- og/eller computerkon- 
ferencer. Det essentielle for anvendelsen af den nye teknologi har været de øgede muligheder for fleksibel kommunikation, diskussion og samarbejde.

Der er ingen tvivl om at det danske koncept for fjernundervisning og netbaseret undervisningen er effektivt. Sammenlignet med andre lande - både inden for traditionel fjernundervisning og elæring - er frafaldet blandt de studerende i Danmark moderat. Det ser også ud til at EU har fået øjnene op for at samspillet mellem lærer og elev/studerende er essentielt for en god læreproces. Så lad mig slutte af med at citere kommissær Redings (DG: Youth \& Culture) tale ved åbningen af LEARNTEC konferencen i Karlsruhe den 4. februar 2003:

Modern e-learning solutions now recognise the importance of learning as a social process and offer possibilities for collaboration with other learners, for interaction with the learning content and for guidance from teachers, trainers and tutors. The learner-centric approaches have put the learner back in command, with a wealth of learning resources at their fingertips.

Teachers and trainers once more play a central role, using virtual and traditional faceto-face interaction with their students in a "blended" approach. An approach in which they are no longer seen simply as consumers of pre-determined e-learning content, but as editors, authors and contributors to a contextualised learning scenario. (fremhævningerne er fra originalteksten).

Her understreges netop de danske kvaliteter: at læring er en social proces baseret på samarbejde mellem de studerende indbyrdes og med læreren involveret som medspiller både on-line på nettet og i klasseværelset face-to-face med de studerende. Det nye buzz-word i EU-ansøgninger er blevet "blended learning"!

Selvom det danske koncept for netbaseret undervisning således har medvind bør vi ikke slå os til tåls. Dansk netbaseret undervisning har fortsat behov for videreudvikling gennem samarbejde institutionerne imellem.

\section{Litteratur}

European Commission. The eLearning Action Plan, COM (2001) 172 final.

Fjuk, Annita \& Lone Dirckinck-Holmfeld. "Sammenføyningsarbeid i distribuerte kollektive læreprocesser". Laering og multimedier. Red. Oluf Danielsen. Aalborg: Aalborg Universitetsforlag, 1997.

Harasim, Linda. "Online Education: A New Domain". Mindweave. Communication, Computers and Distance Education. Red. Robin Mason \& Anthony Kaye. Oxford: Pergamon Press, 1988. 50-62

Heilesen, Simon: "CSCW som grundlag for distribueret netbaseret undervisning og læring". Uddannelse, Laering og IT. Uddannelsesstyrelsen: Undervisningsministeriet 2002. 79-86

Katz, Richard N. \& Diana G. Oblinger: The "E" Is for Everything. E-Commerce, E-Business, and E-Learning in Higher Education. San Francisco: Jossey-Bass, 2000.

OECD: E-Learning. The Partnership Challenge. Paris: OECD Publications, 2001.

Reding, Viviane: "Is e-learning going mainstream?" Opening of the Learntec Forum, Karlsruhe, 4 February 2003. DN: SPEECH/03/48. Online:

$<$ http://europa.eu.int/rapid/start/cgi/guesten.ksh?p_action.gettxt=gt\&doc=SPEECH/03/48|0| AGED\&lg=EN\&display=> (downloaded 14.9.2003). 